\title{
A AVALIAÇÃO EM EDUCAÇÃO PROFISSIONAL E TECNOLÓGICA: ABORDAGENS PARA UMA SISTEMATIZAÇÃO NOS PROCESSOS DE AVALIAÇÃO
}

\author{
EVALUATION IN PROFESSIONAL AND TECHNOLOGICAL \\ EDUCATION: APPROACHES FOR A SYSTEMATIZATION IN \\ EVALUATION PROCESSES
}

\author{
Anderson Ferreira Gomes ${ }^{21}$ \\ Thiago de Lima Silva ${ }^{22}$ \\ Gian Mendes Ribeiro ${ }^{3}$ \\ Diogo Pereira Bezerra4
}

A educação no Brasil é marcada por uma dualidade existente até o século XIX, onde a educação propedêutica atendia aos interesses da elite. Os primeiros registros de Educação Profissional no Brasil se dão em 1809 quando D. João VI cria o Colégio das Fábricas. A partir disso, nesse mesmo século criaram-se instituições de caráter assistencialista que embora venham sofrendo constantes reformas ao longo do tempo ainda se caracterizam pelo enfrentamento a dualidade estrutural da sociedade brasileira através da transformação do indivíduo e sua inserção no mundo do trabalho.

Com a criação dos Institutos Federais de Educação Ciência e Tecnologia, por meio da Lei no 11.892, de 29 de dezembro de 2008, a Educação Profissional e Tecnológica ganhou grande destaque. Bem fundamentada em suas bases teóricas, as discussões entre os pesquisadores/educadores em EPT ainda são recentes. Partindo dessa nova realidade

\footnotetext{
${ }^{21}$ Aluno do curso de pós-graduação stricto senso em Educação Profissional e Tecnológica - Bacharel em Música pela Universidade Federal de Campina Grande e Servidor Público Federal lotado no Instituto Federal de Educação, Ciência e Tecnologia do Ceará. E-mail: anderson.gomes@ifce.edu.br

${ }^{22}$ Aluno do curso de pós-graduação stricto senso em Educação Profissional e Tecnológica - Bacharel em Biblioteconomia pela Universidade Federal da Paraíba e Servidor Público Federal lotado no Instituto Federal de Educação, Ciência e Tecnologia da Paraíba. E-mail: thiagobibliotecario@gmail.com

${ }^{3}$ Doutorado em Educação Musical pela Universidade do Rio Grande do Sul - Professor Artes/Música do IFRN 4 Doutorado em Engenharia Química pela Universidade Federal do Ceará - Professor área Química do IFRN e professor do Mestrado Profissional em Educação Profissional e Tecnológica - ProfEPT.
} 
educacional buscamos como objetivo geral compreender, dentro das práticas educativas, os processos de avaliação para EPT, e sugerir um processo de sistematização desses processos que dialoguem com suas bases teóricas. Dessa maneira buscamos caminhos para um processo de avaliação que, dentro do processo ensino-aprendizagem, auxiliem no crescimento e desenvolvimento integral do aluno, prerrogativa mister dentro da EPT.

Como problema de pesquisa nos aprouve indagar? Diante deste cenário, como avalia a EPT? E como é avaliada? Visando uma educação promissora, que rompa com os paradigmas estruturais e a dualidade educacional histórica, entendemos que a avaliação para a educação profissional deve estar pautada na relação entre teoria e prática, visando a autonomia, transformação e emancipação do indivíduo para o mundo do trabalho.

A pesquisa possibilitou a compreensão de que, a sistematização das práticas educativas no quesito "processos avaliativos", ainda em alinhamento as prerrogativas das bases teóricas da EPT, é de suma importância para o desenvolvimento de uma nova realidade no processo ensino-aprendizagem a que se compromete este modelo de educação.

Desse modo, na primeira seção nos atentamos a fazer uma breve caminhada pela trajetória da EPT, de maneira a situar o leitor a respeito de sua história, suas conquistas e sua essência.

Na segunda seção, tratamos do objeto de estudo em questão, os processos avaliativos em EPT. Vislumbramos caminhos para uma sistematização das práticas educativas relativas aos métodos de avaliação que se comprometam com uma formação integradora para o mundo do trabalho.

E se tratando de avaliação, na terceira seção, suscitamos o diálogo entre a EPT e os mecanismos de avaliação externa, tendo em vista que a utilização de instrumentos de avaliação corretos tornam-se primordiais para o curso da EPT.

Por fim apresentamos que este artigo teve por finalidade realizar um levantamento bibliográfico da avaliação em EPT, avaliamos a necessidade de sistematização dos processos avaliativos através de um mapa construtivo avaliativo interno e externamente. 


\section{UMA BREVE TRAJETÓRIA DA EDUCAÇÃO PROFISSIONAL E TECNOLÓGICA}

Com o pensamento pautado na indústria no início do século $X X$ a preparação para o trabalho influenciou na educação na implementação de ações na área da educação profissional e tecnológica sendo oficializadas quando Nilo Peçanha assumiu a Presidência da República e que por meio do Decreto no 7.566, de 23 de setembro de 1909, criou as Escolas de Aprendizes Artífices, mantidas pelo Ministério da Agricultura, Comércio e Indústria com o objetivo de ofertar à população o ensino profissional gratuito.

Essas escolas eram instituições para a classe trabalhadora para a formação de mão de obra especializada com o objetivo de atender ao desenvolvimento industrial do país, "mediante ensino prático e conhecimentos técnicos necessários aos menores para que pretendessem aprender um ofício, em oficinas de trabalho manual ou mecânico que forem mais convenientes" (CUNHA, 2000, p. 63).

Nas décadas de 1930 a 1940 o campo educacional seguiu o ideário populista, com o objetivo de estender às massas populares o direito à educação escolar. Com a Reforma Francisco Campos no ano de 1931, organizou o ensino comercial, por meio do Decreto no 20.158 de 20 de junho de 1931, o ensino secundário, por meio do decreto no 19.890 , de 18 de abril de 1931 e o ensino superior, por meio do decreto no 19.851, de 11 de abril de 1931 que além do caráter normatizador, teve também o objetivo de organizar e regular a política educacional brasileira nos seus diferentes níveis. Esse decreto assinalou a possibilidade de uma política centralizada também para a educação profissional e tecnológica que a partir da criação do Ministério da Educação e Saúde Pública, teve as Escolas de Aprendizes Artífices sob sua jurisdição e estabelecendo um sistema nacional de formação profissional com a criação do Serviço Nacional de Aprendizagem dos Industriários (SENAI) por meio do Decreto Lei $n$ o 4.408, de 22 de janeiro de 1942, denominação alterada pelo Decreto Lei no 4.936, de 7 e novembro desse mesmo ano, cujo objetivo era a formação de profissionais para o processo de industrialização em expansão. De acordo com Nosella: 
[...] com o advento da industrialização, comumente datada dos anos 30 deste século, organizou-se o ensino profissional com o objetivo de formar a mão de obra especializada para a indústria (técnicos). Dessa forma, estava instituída a dualidade e com ela a bandeira da escola única. Como não lembrar a proposta de escola única de Anísio Teixeira? Seria uma escola igual para todas as crianças, a despeito de suas diferentes origens e diferentes destinos sociais (NOSELLA, 2002, p. 85).

O Serviço Nacional de Aprendizagem Comercial (SENAC) foi criado por meio do Decreto Lei $\mathrm{n}$ - 8.621, de 10 de janeiro de 1946, tendo como objetivo a oferta em larga escala, da educação profissional destinada a formação de trabalhadores para o comércio. Os cursos iniciais tinham como público jovens com idade entre 14 a 18 anos, praticantes do comércio e também cursos voltados para o comerciário adulto que quisessem ampliação de conhecimentos.

Em 1959 as Escolas Industriais e Técnicas foram transformadas em autarquias com o nome de Escolas Técnicas Federais com autonomia didática e de gestão intensificando-se a formação de técnicos devido ao processo de industrialização da época.

A Lei no 5.692, de 11 de agosto de 1971 tornou compulsório o ensino técnicoprofissional de segundo grau com o foco de formar técnicos sob o regime de urgência. Nessa década o Senac passou a ofertar cursos de Aprendizagem (nível de ensino fundamental), Qualificação, Aperfeiçoamento e Atualização (níveis de ensino fundamental e médio) e Habilitação (nível de ensino médio).

A década de 1980 exigiu dos trabalhadores novos conhecimentos e novas exigências educacionais para sua formação. A Carta Constitucional de 1988 consubstanciou uma consolidação de direitos sociais, dentre os quais a educação e seu papel na sociedade sendo uma estratégia importante na busca da superação das novas necessidades.

A década de 1990 passou a exigir das escolas de educação profissional e tecnológica voltada para a capacidade técnica, comunicativa e participativa com o objetivo de estimular a autonomia na tomada de decisões e a capacidade de antever os problemas os problemas e solucioná-los.

A expansão e a reforma do ano de 1997 implementadas pelo governo federal através de políticas públicas tinham como objetivo a reorganização da educação profissional e tecnológica tendo como prioridade os trabalhadores que necessitavam encurtar o caminho entre a escola e o mercado de trabalho com uma formação de nível básico voltada para o 
setor de serviços, incentivando assim, a capacidade competitiva do país na economia mundial.

Nessa reconfiguração da educação profissional e tecnológica o Proep surge através do Decreto no 2.208, de 17 de abril de 1997 tendo como objetivo a implantação da reforma da educação profissional e tecnológica, determinada pela Lei de Diretrizes e Bases da Educação abrangendo financiamento de construção de prédios, aquisição de equipamentos de laboratórios e material pedagógico como ações voltadas para o desenvolvimento técnicopedagógico e de gestão de escolas. O Proep buscou recursos através do Banco Mundial e de acordo com Ramos (2014):

[...] destinava-se à expansão da educação profissional em determinadas condições. O aumento do número de instituições, por exemplo, só ocorreria pela iniciativa dos estados ou dos municípios, isoladamente ou em associação com o setor privado; ou, ainda, por meio de entidades privadas sem fins lucrativos, isoladamente ou em associação com o setor público (RAMOS, 2014, p. 60).

As características do Proep tiveram uma dualidade estrutural entre educação intelectual e a laboral, devido a separação entre o ensino médio e a educação profissional e tecnológica. Ao longo da história, essa dualidade configurou-se uma categoria explicativa Educação Profissional no Brasil.

Através do documento Programa de Governo 2002 foi proposta uma nova identidade que superasse o dualismo representado pelas dicotomias 'geral e específico', 'técnico e político', ao estabelecer um nexo entre teoria e prática, articulando o pensar e o agir.

Em 23 de julho de 2004, foi promulgado, após longos debates, o Decreto no 5154, que regulamentou $\mathrm{o}_{\S} 2^{\circ}$ do art. 36 e os arts. 39 a 41 da Lei de Diretrizes e Bases da Educação Nacional, com destaque para a possibilidade de articulação entre Educação Profissional e Tecnológica técnica de nível médio e o ensino médio nas formas integrada, concomitante e subsequente.

A expansão de 2006, teve como objetivo a implantação de escolas federais de formação profissional e tecnológica em estados ainda desprovidos dessas instituições em que os cursos estivessem articulados com as potencialidades locais de geração de trabalho corroborando com a inclusão social emancipatória tendo como ponto de vista a crescente 
reponsabilidade da produção de conhecimentos, gerando saberes e desenvolvendo competências com caráter crítico e reflexivo para a contribuição assim para a elevação da escolarização.

A criação dos Institutos Federais de Educação. Ciência e Tecnologia, por meio da Lei no 11.892 , de 29 de dezembro de 2008 colocou em maior destaque a educação profissional e tecnológica oferecendo cursos de formação inicial e continuada, cursos técnicos, cursos superiores de tecnologia, licenciatura, bacharelado e programas de pós-graduação.

A educação profissional e tecnológica necessita de um diálogo entre as políticas sociais e econômicas com os enfoques locais e regionais reconhecendo essa modalidade de ensino como fator estratégico e de suma importância para o crescimento local e regional.

\section{CAMINHOS PARA AVALIAÇÃO NA EPT: FORMAÇÃO PARA O MUNDO DO TRABALHO}

De acordo com os pressupostos teóricos que compõe as bases da Educação Profissional e Tecnológica (EPT), o trabalho é característica essencial que constitui o homem em sua totalidade. Segundo Saviani (2007, p. 154): “O ato de agir sobre a natureza transformando-a em função das necessidades humanas é o que conhecemos com o nome de trabalho". Portanto, depreende-se desse processo que o homem aprende a ser homem a partir do momento em que se relaciona com a natureza a transformando e sendo transformado, constituindo-se assim um processo educativo. Esta é a origem da educação, que coincide então, com a origem do próprio homem. De acordo com Saviani (2007):

Diríamos, pois, que no ponto de partida a relação entre trabalho e educação é uma relação de identidade. Os homens aprendiam a produzir a sua própria existência no próprio ato de produzi-la. Eles aprendiam a trabalhar trabalhando (SAVIANI, 2007, p. 154).

A partir dessas explanações poderemos compreender a fundamental relação entre trabalho e educação. Mas é consenso que ao longo da história trabalho e educação não 
andaram tão próximos assim. Com o desenvolvimento da produção foi criado uma ruptura de classes, sendo criadas duas classes sociais fundamentais: a classe dos proprietários e a dos não proprietários. Com isso Saviani (2007) afirma:

O advento da propriedade privada tornou possível à classe dos proprietários viver sem trabalhar. Claro. Sendo a essência humana definida pelo trabalho, continua sendo verdade que sem trabalho o homem não pode viver. Mas o controle provado da terra onde os homens vivem coletivamente tornou possível aos proprietários viver do trabalho alheio; do trabalho dos não-proprietários que passaram a ter a obrigação de, com seu trabalho, manterem-se a si mesmos e ao dono da terra, convertido em seu senhor (SAVIANI, 2007, p. 154).

Com a divisão dos homens em classe ocorre também uma divisão na educação. Com mais tempo disponível os "proprietários" dispunham de tempo para atividades intelectuais, lúdicas e de lazer. Desenvolveu-se, a partir daí um novo tipo de educação, voltada para estes que dispunham de tempo livre. Ainda de acordo com Saviani (2007) essa nova forma de educação passou a ser identificada como o principal modelo de educação, impetrando-se assim a separação entre educação e trabalho e fortalecendo a divisão de classes.

Pautados nas noções de politecnia e inspirada nas reflexões de Gramsci sobre trabalho como princípio educativo da escola unitária, assim a EPT suscita o diálogo entre as políticas sociais e econômicas com os enfoques locais e regionais reconhecendo essa modalidade de ensino como fator estratégico para o rompimento da dicotomia trabalho/educação através de seus pressupostos teóricos, favorecendo a formação omnilateral do indivíduo e consequentemente sua ascensão ao mundo do trabalho. De acordo com GOMES; SILVA; MOREIRA (2015):

A reordenação sociopolítica e econômica que está ocorrendo no país e as demandas tecnológicas repercutem no mercado de trabalho provocando uma reorganização na educação profissional. Atualmente os jovens precisam ingressar no mundo do trabalho, não só com conhecimentos técnicos adquiridos, mas com outras competências como saber trabalhar em equipe; ser capaz de tomar iniciativas; e contribuir através da sua atividade profissional com as transformações sociais (GOMES; SILVA; MOREIRA 2015, p. 02). 
Destacamos que dentre as práticas educativas em EPT, os processos de avaliação compõe uma etapa fundamental nos processos de ensino-aprendizagem visando a formação profissional para este novo mercado de trabalho. E como avaliar este aluno? Para GOMES; SILVA; MOREIRA (2015): "Para a educação profissionalizante, a avaliação é singular pela necessidade de atender aos pressupostos básicos educacionais pautadas na inter e transdiciplinaridade relacionando teoria e prática". Desse modo destacamos que a avaliação da aprendizagem se constitui numa prática complexa, mas fundamental na formação desse novo profissional.

A Educação Profissional tem sido objeto de amplas discussões no âmbito acadêmico, havendo um desenvolvimento exponencial de pesquisas nesta área. Contudo, a presente pesquisa compreendeu que no campo das práticas educativas os processos de avaliação são pouco mencionados, havendo poucos registros de discussões sobre o assunto relacionado a Educação Profissional e Tecnológica (EPT). Sendo esta uma recente realidade da educação brasileira, buscou-se compreender quais os caminhos para a sistematização dos processos de avaliação que se entrelacem as bases teóricas constituintes da EPT.

De acordo com Oliveira:

O ato de avaliar é amplo e não se restringe a um único objetivo (...). Não consiste em só avaliar o aluno, mas o contexto escolar na sua totalidade, permitindo fazer um diagnóstico para sanar dificuldades do processo de aprendizagem, no sentido teórico e prático (OLIVEIRA, et al., 2017).

Para Oliveira a avaliação é um instrumento que pode ser utilizado para análise dos diversos elos do processo de ensino e aprendizagem: o aluno, o professor e todo o contexto escolar. A avaliação pode e deve ser utilizada como um instrumento de aprimoramento do cotidiano escolar como um todo.

Segundo Chueri (2008):

A avaliação escolar é um meio e não um fim em si mesma, está delimitada por uma determinada teoria e por uma determinada prática pedagógica. Ela não ocorre num vazio conceitual, mas está dimensionada por um modelo teórico de sociedade, de homem, de educação e, consequentemente, de ensino e de aprendizagem, expresso na teoria e na prática pedagógica (CHUERI, 2008, p. 51). 
Entendemos, pois, que só através da reflexão é possível adquirir consciência crítica sobre os processos de ensino-aprendizagem e através disso proporcionar o desenvolvimento do aluno e de sua emancipação enquanto indivíduo.

\section{Abordagens do processo de ensino e avaliação em Mizukami}

Nesta seção analisamos a obra "Ensino: as abordagens do processo" de Maria da Graça Nikoletti Mizukami, que faz parte da coleção Temas Básicos de Educação e Ensino que tem como finalidade oferecer subsídios e sugestões para educadores em geral.

As principais abordagens discutidas por Mizukami foram desenvolvidas como novos paradigmas acerca da concepção de homem e sociedade. No texto a autora trabalha cinco abordagens metodológicas de ensino, a saber: Abordagem tradicional, abordagem comportamentalista, abordagem humanista, abordagem cognitivista e abordagem sóciocultural. E no âmbito destas abordagens, nos atentaremos aos critérios de avaliação em que a EPT pode se apoiar para uma educação inovadora que se comprometa com a emancipação do indivíduo.

Para nós, estudiosos da educação, em especial das relações entre trabalho e educação, a abordagem sócio cultural se mostra muito relevante para concretização de uma educação transformadora. De acordo com os pressupostos desta abordagem Paulo Freire (1975) se posiciona: "ninguém educa ninguém, ninguém se educa, os homens se educam entre si, mediatizados pelo mundo". Com base no trabalho de Paulo Freire, essa abordagem defende um ensino em que o educador e o educando desenvolvam o pensamento reflexivo, tornando-se sujeitos da aprendizagem. Desse modo, no contexto da EPT, esta abordagem muito se aproxima das bases teóricas e pressupostos filosóficos, tendo em vista que busca uma educação libertadora e emancipadora para os sujeitos. De acordo com Mizukami (1986):

O homem chegará a ser sujeito através da reflexão sobre seu ambiente concreto: quanto mais ele reflete sobre a realidade, sobre sua própria situação concreta, mais se torna progressiva e gradualmente consciente, comprometido a intervir na realidade para muda-la (MIZUKAMI, 1986, p. 86). 
Nesse âmbito, a escola deve ser o espaço que vai contribuir com a promoção do indivíduo que terá autonomia para mudar a sua realidade, se distanciando de uma educação reprodutivista que funciona apenas como ajuste deste indivíduo a sociedade existente.

Sobre avaliação, Paulo Freire (1982) diz: "a avaliação é uma prática educativa, e não um pedaço dela". Dito isto, na abordagem sócio-cultural o processo de avaliação ocorre por meio da auto-avaliação e /ou da avaliação mútua e permanente da prática educativa entre professor e alunos. Nesta lógica, utilizando-se de um "auto-reflexão" educandos e educadores saberão quais os seus progressos e também onde se encontram suas dificuldades. Considerando esse aspecto, todo aquele processo formal de avaliação contendo exames, notas, etc. passa a não fazer sentido nesse tipo de abordagem.

Percebe-se, portanto, que a metodologia dessa abordagem é ativa, crítica e dialógica: o professor busca promover atividades que tenham relação com o cotidiano do estudante e que desenvolvam a autonomia e conscientização deste, buscando a transformação da realidade dos jovens.

No que concerne a abordagem humanista, esta veio romper com paradigmas tradicionais cujo enfoque era centrado no processo em detrimento a formação humana no sentido da filosofia da práxis. Cuja dimensão filosófica existencialista é acrescida nesse processo de formação do homem para atuarem em sociedade. Privilegiar abordagens como estas nos processos de formação do homem é primordial para o rompimento da ideia homem-objeto, que obedece estritamente aos interesses do capital.

Essa abordagem é norteada pela ideia de que o sujeito traz consigo condições de conhecimento e aprendizagem que irão se manifestar durante o seu amadurecimento. Nesta perspectiva a escola deveria contribuir com o desenvolvimento do aluno e também fornecer condições para que a autonomia do educando seja alcançada, discussão importantíssima para a materialização da EPT. No estudo da obra de Mizukami fica claro o comprometimento da abordagem Humanista para com a promoção do desenvolvimento e autonomia do indivíduo (aluno). Nessa abordagem o aluno é tido como sujeito do conhecimento enquanto o professor adquire a imagem de facilitador da aprendizagem. Por se destacar como uma abordagem libertadora, quebrando paradigmas postos por outros modelos tradicionais, esta concepção de ensino muito se assemelha aos pressupostos da EPT. Ademais, essa 
abordagem configura-se como uma das mais relevantes para um processo de ensinoaprendizagem que deseje o desenvolvimento efetivo dos educandos.

Se tratando de métodos ou processos avaliativos de acordo com Rogers (1972):

\begin{abstract}
Quando reunimos em um esquema elementos tais como currículo preestabelecido, "deveres idênticos" para todos os alunos, preleções como quase único modo de instrução, testes padronizados pelos quais são avaliados externamente todos os estudantes, e notas dadas pelo professor, como modo de medir a aprendizagem, então, quase podemos garantir que a aprendizagem dotada de significados será reduzida a expressão mais simples (ROGERS, 1972, p. 5).
\end{abstract}

Rogers (1972) defende a autoavaliação, e é aí onde as duas abordagens, humanista e sócio-cultural, caminham juntas na concepção de um método de avaliação com vistas a emancipação do sujeito. O processo de auto-avaliação se mostra eficaz por proporcionar ao educando a realização do auto-engrandecimento, maior abertura para exposição e compartilhamento de suas experiências e desenvolvimento próprio indivíduo.

Rogers (1972), ainda afirma que: "a avaliação de cada um de sua própria aprendizagem é um dos melhores meios pelo qual a aprendizagem auto-iniciada se torna aprendizagem responsável.

Desse modo compreendemos a utilização de tais abordagens do processo de ensino, de suas propostas metodológicas e de avaliação como grandes aliadas na concepção de uma educação libertadora, emancipadora, pautada nas concepções de politecnia, da escola unitária e do ensino integral, objetivando a formação omnilateral do aluno e sua ascensão ao mundo do trabalho.

\title{
AVALIAÇÃO EXTERNA EM EDUCAÇÃO PROFISSIONAL E TECNOLÓGICA
}

A avaliação externa é um processo que identifica aspectos como fragilidade, excelência e qualidade dos cursos tendo como principais particularidades a ser conduzida por comissões externas; atuando na interdisciplinaridade das generalidades e das especificidades do objeto que está sendo avaliado; articulando com a avaliação interna 
institucional sempre pautando na base legal, nas diretrizes nacionais e nos documentos institucionais.

Os resultados desses processos têm como objetivos principais recomendações para o aprimoramento e melhorias dos cursos e programas desenvolvidos, ou seja, a avaliação externa tem como objetivo diagnosticar a qualidade do sistema da EPT contribuindo para a elaboração de políticas públicas para o redirecionamento da função social.

O termo avaliação quando aplicado na área da educação passa a ter um importante significado, oferecendo elementos fundamentais para a adequação do redirecionamento de políticas públicas, bem como da gestão da implementação dessas políticas, em uma área considerada primordial para o desenvolvimento do Brasil.

A temática que envolve a avaliação em EPT é recente. No contexto da revisão da literatura, esse tipo de avaliação é citado sob diversas denominações como "avaliação em larga escala", "avaliação externa" e "avaliação sistêmica". Essas avaliações são aplicadas por fontes externas às instituições de ensino em datas com agendamento prévio e que são aplicadas no âmbito do sistema escolar, objetivando o fornecimento de informações aos órgãos do governo com diretrizes em suas políticas públicas na área da educação desenvolvendo um conjunto de processos avaliativos, com diversos interesses, formatos e propostas de aplicação.

Avaliações externas também são caracterizadas através de procedimentos de aplicação de testes e instrumentos para medir um diagnóstico da aprendizagem do educando para um determinado grau de escolaridade. Esse tipo de avaliação aprecia aspectos cognitivos específicos deixando de prestigiar outras dimensões da formação desses alunos menos valorizadas socialmente (BARRETO, 2001).

Os sistemas de avaliação da educação básica e do ensino superior vem ao longo dos anos aprimorando e até mesmo amadurecendo, mas o que acontece é que no âmbito da EPT não existe um sistema que possa fazer uma avaliação a nível nacional existindo apenas uma avaliação de resultados com pesquisas que levam em consideração apenas os estudos de impactos em relação aos cursos na vida de seus alunos e também tendo como foco o mercado de trabalho, sendo este de forma mais localizada. Os mecanismos oficiais de certificação de competências é uma alternativa de proposta avaliativa desses resultados de 
aprendizagem em EPT, mas que ainda não foram discutida, amadurecida e implantada de forma a garantir esses resultados.

\section{CONSIDERAÇÕES FINAIS}

Este artigo teve por finalidade realizar um levantamento bibliográfico da avaliação em EPT o que levou a verificar que ainda não existem instrumentos próprios implementados para esse tipo de ensino de forma universalizada, muitas vezes se utilizando de instrumentos já existentes. A avaliação tem como objetivo verificar se as ações executadas estão sendo satisfatórias para determinada instituição de ensino.

Utilizar-se de instrumentos de avaliação corretos tornam-se primordial para que possa ser dada a tomada de decisão correta. Precisa de sistematicidade, ou seja, com perguntas mapeadas direcionada para qual objetivo está sendo trabalhada nessa avaliação construindo com isso um mapa construtivo avaliativo interno e externamente.

\section{REFERÊNCIAS}

BARBOSA, E. F.; MOURA, D. G. de. Metodologias ativas de aprendizagem na Educação Profissional e Tecnológica. B. Tec. Senac, Rio de Janeiro, v. 2, n. 39, p. 48-67, 2013.

BARRETO, E. S. de S. Avaliação na educação básica nos anos 90. São Paulo: Cortez, 2001.

BRASIL. Decreto 5.154, de 23 de julho de 2004. Regulamenta o § 20 do art. 36 e os arts. 39 a 41 da Lei no 9.394, de 20 de dezembro de 1996, que estabelece as diretrizes e bases da educação nacional e dá outras providências. Disponível em: http://www.planalto.gov.br/ccivil_03/_ato2004-2006/2004/decreto/d5154.htm. Acesso em 01 mar. 2020.

Brasil. Lei no 11.892, de 29 de dezembro de 2008. Institui a Rede Federal de Educação Profissional, Científica e Tecnológica, cria os Institutos Federais de Educação, Ciência e Tecnologia, e dá outras providências. Disponível em:

http://www.planalto.gov.br/ccivil_03/_Ato2007-2010/2008/Lei/L11892.htm. Acesso em: 02 mar. 2020. 
CHUERI, M. S. F. Concepções sobre a avaliação escolar. Revista Estudos em Avaliação Educacional, Fundação Carlos Chagas, São Paulo, v. 19, n. 39, p.49-64, jan./abr. 2008.

CUNHA, L. A. O ensino profissional na irradiação do industrialismo. 2. ed. São Paulo: Editora da Unesp, 2000.

FREIRE, P. Uma Educação para a Liberdade. Porto: Textos marginais, 1975.

Educação, O sonho impossível. In: BRANDÃO, C. R. (Org.), Educador: Vida e Morte. Rio de Janeiro: Graal, 1982. p. 89-101.

GOMES, F.; SILVA, J.; MOREIRA, C. Avaliação da aprendizagem na educação profissional técnica de nível médio: uma reflexão crítica. Colóquio Nacional - A produção do conhecimento em Educação Profissional, Natal, 2015.

MIZUKAMI, M. da G. N. Ensino: as abordagens do processo. São Paulo: Editora Pedagógica e Universitária Ltda., 1986. (Temas básicos de educação e ensino).

NOSELLA, P. Qual compromisso político? Ensaios sobre a educação brasileira pós ditadura. Bragança Paulista: EDUSF, 2002. Porto Alegre: Artes Médicas Sul, 1992.

OLIVEIRA, A.; APARECIDA, C.; SOUZA, G. M. R. Avaliação: Conceitos em diferentes olhares, uma experiência vivenciada no curso de pedagogia. Disponível em: http://www.pucpr.br/eventos/educere/educere2008/anais/pdf/510_223.pdf. Acesso em: 17 abr. 2017.

RAMOS, M. N. História e política da educação profissional. Curitiba: Instituto Federal do Paraná, 2014.

ROGERS, C. Liberdade para Aprender. Belo Horizonte, Interlivros, 1972.

SAVIANI, D. Trabalho e educação: fundaentos ontológicos e históricos. Revista Brasileira de Educação, Campinas - Sp, v. 12, n. 34, p. 152-180, 2007. 